\title{
PRECIPITATION OF SALTS
}

BY A. ERNEST TAYLOR

At the suggestion of Prof. Bancroft I have undertaken a few experiments on the precipitation of salts from aquenus solutions by alcohol or acetone. Work exactly similar to this has recently been done by Bathrick. ${ }^{1}$ He found that his results could be expressed by an equation of the general form $(x+A) y^{\prime \prime}=C$, where $x$ and $y$ represent respectively the weight of alcohol and of salt in a fixed weight of water. Bancroft ${ }^{2}$ had previously used this equation to describe the solubility of various salts in alcohol containing varying percentages of water, as taken from the data given by Gérardin ${ }^{3}$ and Bodländer. ${ }^{4}$

The method of experimentation which I employed was very much the same as that used by Bathrick. The alcohol, which at first contained but a trace of water, was distilled from lime; then after standing over dehydrated copper sulphate for a day or two was again distilled. This last operation was usually repeated. Copper sulphate was added as long as any blue color was perceptible. This alcohol, as soon as distilled, was immediately made up gravimetrically into solutions containing from ten to ninety-five percent of water, care being taken that the solutions be accurate within a few hundredths of a percent. These solutions were then preserved in carefully stoppered bottles, which had been thoroughly cleaned and boiled out with steam. Small bottles, similarly cleaned, were used for the solubility determinations. At first glass stoppers were tried, but rubber stoppers seemed to prevent more effectually any error

Journ. Phys. Chem. I, I56 (1896).

arbid. I, 33 ( I896).

3Ann. Chim. Phys, (4) 5, I29 (I865).

4Zeit. phys. Chem. 7, 308 (ISgI). 
from evaporation. When solutions of acetone were used, cork stoppers were substituted. These small bottles, containing the aqueous alcohol and a large excess of very finely powdered salt, were placed in an Ostwald thermostat for about half a day at a temperature some ten degrees higher than that at which the solubility was to be determined. During this time the bottles were shaken frequently and thoroughly. The temperature was then lowered and carefully maintained at the desired point for about a day, at the end of which time a measurement was made, and repeated two or three times at intervals a day apart. In no case did I observe any trace of supersaturation. At first I made up my solutions at the desired temperature, making a measurement at the end of a day, as described by Bathrick. This did not give me accurate results, for on repeating the measurements I found the solubility to increase. In some cases it approached very nearly a constant at the end of three days; but, at least six days were required for many measurements. I determined the solubility of sodium chloride at $40^{\circ}$ by both methods, and found the results to agree well. The last method, however, admits of much more possibility of error from evaporation and other causes, by reason of the greater length of time required. With potassium bromide I found it almost impossible to determine the saturation point by this method.

The salts used were all from Bender and Hobein, and of the purest quality marked $\mathrm{Ph}$. III, with the exception of the potassium chlorate. The sodium chloride and potassium bromide were simply fused after being tested for impurities. The sodium nitrate and potassium chlorate were recrystallized two or three times and dried in an air bath. I could detect no trace of nitrite in the sodium nitrate after drying, nor in the solutions after the solubility had been determined. The aqueous solutions of acetone were made up by Mr. Snell, the acetone used having been prepared with great care so that it distilled within a fraction of a degree.

The solubilities were determined by taking out about $5 \mathrm{cc}$ of the saturated solution, weighing it and then determining the amount of salt left on evaporation according to the method described by Trevor. ${ }^{1}$

זZeit. phys. Chem. 7, 468 (I89I). 
The pipette used for taking out the solutions was usually warmed to prevent any precipitation of salt in it. The weighings were made accurate to a milligram. The values determined for the amount of salt in one gram of solution seldom varied more than a milligram, and in case the solubility was not too great the values obtained were somewhat more accurate than that. The values for the amount of salt in one gram of water, of course, had a somewhat greater error, increasing with the concentration of the alcohol. Measurements were made at $30^{\circ}$ and at $40^{\circ}$ with aqueous solutions of alcohol and acetone. The results are given in Tables $I-X$. In the first column are given the percentages by weight of alcohol or acetone in the aqueous solutions ; in the second and third the weight of salt contained in one gram of saturated solution, as calculated and as observed respectively; in the third and fourth, the amount of salt contained in one gram of water, as calculated and as observed. The amount of alcohol in one gram of water is represented by $x$, the amount of salt in one gram of water by $y$ and in one gram of saturated solution by $y^{1}$. When two formulae are used to represent the results given in any one table, the second formula always refers to the results which come below the dotted line.

TABLE I

Alcohol : $\mathrm{KClO}_{3}$ at $30^{\circ}$

$$
\begin{array}{ll}
(\mathrm{x}+0.20) \mathrm{y}^{1.57}=\mathrm{C}_{1} & \log \mathrm{C}_{1}=7.740-10 \\
(\mathrm{x}+0.20) \mathrm{y}^{1.2}=\mathrm{C}_{2} & \log \mathrm{C}_{2}=8.310-10
\end{array}
$$

\begin{tabular}{|c|c|c|c|c|c|}
\hline \% Alc. & $y^{\prime}$ calc. & $y^{\prime}$ obs. & y calc. & y obs. & $\log \mathrm{C}$. \\
\hline o & 0.0920 & 0.0923 & O. IOI 3 & 0.1017 & $7.741-10$ \\
\hline 5 & 0.0767 & 0.0772 & 0.0874 & 0.0880 & $7 \cdot 746-10$ \\
\hline IO & 00644 & 0.0644 & 0.0765 & 0.0765 & $7 \cdot 741-10$ \\
\hline 20 & $0.0+60$ & $0.045^{\mathrm{I}}$ & 0.0604 & 0.0590 & $7 \cdot 723-10$ \\
\hline 30 & $0.033 \mathrm{I}$ & $0.032 \mathrm{I}$ & $0.04 \times 9$ & 0.0474 & $7.719-10$ \\
\hline 40 & 0.0234 & 0.0235 & 0.0398 & 0.0400 & $7 \cdot 743-10$ \\
\hline & $-\cdots--1$ & & & - non & \\
\hline $5^{\circ}$ & 0.0165 & 0.0164 & 0.0335 & 0.0333 & $8.306-10$ \\
\hline 60 & 0.0101 & 0.0101 & $0.025 \mathrm{I}$ & 0.0253 & $8.314-10$ \\
\hline $7^{\circ}$ & 0.0054 & 0.0054 & 0.0180 & 0.0182 & $8.316-10$ \\
\hline 80 & 0.0024 & 0.0024 & 0.0118 & 0.0122 & $8.327-10$ \\
\hline 90 & 0.0006 & 0.0006 & $0.006 \mathrm{I}$ & 0.0062 & $8.315-10$ \\
\hline
\end{tabular}


TABLE II

Alcohol: $\mathrm{KClO}_{3}$ at $40^{\circ}$

$$
\begin{array}{ll}
(x+0.22) y^{1.57}=C_{1} & \log C_{1}=8.000-10 \\
(x+0.22) y^{1.2}=C_{2} & \log C_{2}=8.5 \text { I8-10 }
\end{array}
$$

\begin{tabular}{|c|c|c|c|c|c|}
\hline$\%$ Alc. & $y^{\prime}$ calc. & $y^{1}$ obs. & y calc. & y obs. & $\log \mathrm{C}$. \\
\hline $\mathrm{o}$ & O. 1227 & O. 1223 & O. I 397 & o. I 393 & $7 \cdot 999-10$ \\
\hline 5 & O. IO39 & O. 1048 & O. I 2 I 9 & 0.1233 & $8.008-10$ \\
\hline IO & 0.0884 & 0.0884 & 0.1076 & o. 1077 & $8.001-10$ \\
\hline 20 & 0.0643 & 0.0640 & $0.086 \mathrm{I}$ & 0.0856 & $7 \cdot 996-$ Io \\
\hline 30 & 0.0463 & 0.0467 & 0.0693 & 0.0700 & $8.007^{-10}$ \\
\hline 40 & 0.0333 & $0.034 \mathrm{I}$ & 0.0574 & 0.0588 & $8.016-10$ \\
\hline & 4 & & $-1-1$ & 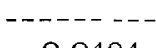 & $-x^{8}-4-1$ \\
\hline 50 & $0.024 \mathrm{I}$ & $0.024 \mathrm{I}$ & 0.0494 & 0.0494 & $8.519-10$ \\
\hline 60 & 0.0146 & 0.0146 & $0.037 \mathrm{I}$ & 0.0369 & $8.516-10$ \\
\hline 70 & 0.0079 & 0.0078 & 0.0266 & 0.0263 & $8.5 \mathrm{I} \mathrm{I}-\mathrm{IO}$ \\
\hline 80 & 0.0034 & 0.0034 & 0.0175 & 0.0173 & $8.5 \mathrm{II}-\mathrm{IO}$ \\
\hline 90 & 0.0009 & 0.0012 & $0.009 \mathrm{I}$ & O.OII 7 & $8.647-10$ \\
\hline
\end{tabular}

TABLE III

Acetone: $\mathrm{KClO}_{3}$ at $30^{\circ}$

$$
\begin{aligned}
& (x+0.20) y^{3.6}=C_{1} \quad \log C_{1}=5.727-10 \\
& (x+0.20) y^{1.55}=C_{2} \quad \log C_{2}=8.240-10
\end{aligned}
$$

\begin{tabular}{c|c|c|c|c|c} 
\% Acet. & $y^{1}$ calc. & $y^{1}$ obs. & y calc. & y obs. & $\log \mathrm{C}$. \\
\hline 0 & 0.0923 & 0.0923 & 0.1017 & 0.1017 & $5.727-10$ \\
5 & 0.0830 & 0.0832 & 0.0953 & 0.0956 & $5.732-10$ \\
9.09 & 0.0763 & 0.0763 & 0.0909 & 0.0909 & $5.728-10$ \\
20 & 0.0611 & 0.0609 & 0.0812 & 0.0810 & $5.724-10$ \\
30 & 0.0493 & 0.0493 & 0.0740 & 0.0740 & $5.727-10$ \\
40 & 0.0390 & 0.0390 & 0.0676 & 0.0676 & $5.726-10$ \\
50 & 0.0300 & 0.0290 & 0.0618 & 0.0598 & $5.675-10$ \\
\hline 60 & 0.0205 & 0.0203 & 0.0520 & 0.0517 & $8.236-10$ \\
70 & 0.0119 & 0.0124 & 0.0402 & 0.0418 & $8.267-10$ \\
80 & 0.0057 & 0.0057 & 0.0290 & 0.0288 & $8.235-10$ \\
90 & 0.0018 & 0.0018 & 0.0175 & 0.0182 & $8.267-10$
\end{tabular}




\section{TABLE IV}

Acetone : $\mathrm{KClO}_{3}$ at $40^{\circ}$

\begin{tabular}{|c|c|c|c|c|c|}
\hline$\%$ Acet. & $y^{1}$ calc. & $y^{1}$ obs. & y calc. & y obs. & $\log C$. \\
\hline o & O. 1223 & 0.1223 & 0.1393 & O.I393 & $6.260-10$ \\
\hline 5 & O. IIII & O. IIIO & $0.13 \mathrm{I} 2$ & O. I 3 I I & $6.259-10$ \\
\hline 9.09 & O. I025 & 0.1028 & O.โ 255 & O. I 260 & $6.266-10$ \\
\hline 20 & 0.0828 & 0.0827 & O. I 28 & O. I I 26 & $6.258-10$ \\
\hline 30 & 0.0670 & 0.0669 & 0.1026 & 0.1024 & $6.258-10$ \\
\hline 40 & $0.053^{6}$ & 0.0536 & 0.0945 & 0.0945 & $6.259-10$ \\
\hline 50 & 0.0415 & 0.0403 & 0.0865 & 0.0840 & $6.2 \mathrm{I} 4-\mathrm{IO}$ \\
\hline 60 & & 9086 & - & & \\
\hline 70 & 0.0168 & 0.0168 & $0.05^{67}$ & 0.0568 & $8.476-10$ \\
\hline 80 & 0.0080 & 0.0079 & 0.04 IO & 0.0397 & $8.453-10$ \\
\hline 90 & 0.0024 & 0.0024 & 0.0247 & 0.0245 & $8.465-10$ \\
\hline
\end{tabular}

TABLE V

Alcohol: $\mathrm{NaNO}_{3}$ at $30^{\circ}$

$$
(\mathrm{x}+0.70) \mathrm{y}^{1.2}=\mathrm{C} \quad \log \mathrm{C}=9.827-10
$$

\begin{tabular}{c|c|c|c|c|c}
\hline$\%$ Alc. & $y^{1}$ calc. & $y^{1}$ obs. & y calc. & y obs. & $\log \mathrm{C}$. \\
\hline 0 & 0.4913 & 0.4910 & 0.9660 & 0.9645 & $9.826-10$ \\
5 & 0.4632 & $0.464 \mathrm{I}$ & 0.9085 & 0.9115 & $9.828-10$ \\
10 & 0.4347 & 0.4350 & 0.8545 & 0.8555 & $9.828-10$ \\
20 & 0.3744 & 0.3742 & 0.7485 & 0.7475 & $9.826-10$ \\
30 & 0.3125 & $0.313 \mathrm{I}$ & 0.6495 & 0.6510 & $9.829-10$ \\
40 & 0.2490 & 0.2514 & 0.5530 & 0.5595 & $9.833-10$ \\
50 & 0.1875 & 0.1894 & 0.4615 & 0.4675 & $9.834-10$ \\
60 & 0.1296 & 0.1297 & 0.3720 & 0.3725 & $9.828-10$ \\
70 & 0.0785 & 0.0781 & 0.2845 & 0.2825 & $9.823-10$ \\
90 & 0.0107 & 0.0121 & 0.1080 & 0.1225 & $9.883-10$
\end{tabular}




\section{TABLE VI}

Acetone: $\mathrm{NaNO}^{3}$ at $30^{\circ}$

$$
\begin{aligned}
& (\mathrm{x}+0.70) \mathrm{y}^{2.16}=\mathrm{C}_{1} \quad \log \mathrm{C}_{1}=9.8 \mathrm{II-10} \\
& (\mathrm{x}+0.70) \mathrm{y}^{1.57}=\mathrm{C}_{2} \quad \log \mathrm{C}_{2}=0.0 \mathrm{I} 6
\end{aligned}
$$

\begin{tabular}{|c|c|c|c|c|c|}
\hline$\%$ Acet. & $y^{1}$ calc. & $y^{1}$ obs. & y calc. & y obs. & $\log \mathrm{C}$. \\
\hline o & 0.4910 & 0.4910 & 0.9645 & 0.9645 & $9.8 \mathrm{I} \mathrm{I-IO}$ \\
\hline 5 & 0.4696 & 0.4696 & O 9320 & 0.9320 & $9.8 \mathrm{I} \mathrm{I-IO}$ \\
\hline 9.09 & 0.4519 & 0.45 I I & 0.9065 & 0.9040 & $9.809-10$ \\
\hline 20 & 04010 & 0 tolo & 0.8370 & $0.837^{\circ}$ & $9 . S I I-I O$ \\
\hline 30 & 0.3510 & 0.3508 & $0.77^{2} 5$ & 0.7720 & $9.810-10$ \\
\hline 40 & 0.2979 & 0.2980 & 0.7070 & 0.7075 & $9.8 \mathrm{II}-\mathrm{IO}$ \\
\hline 50 & 0.2422 & 0.2434 & 0.6400 & 0.6440 & $9.8 \mathrm{I} 7-\mathrm{IO}$ \\
\hline 60 & $0.185 \mathrm{I}$ & o. I 855 & 0.5680 & 0.5695 & $9.814-10$ \\
\hline---1 & -1 & $-7-2-1$ & $x=-1$ & $-1-1$ & $-\cdots$ \\
\hline 70 & O.1315 & O.I3I5 & $0.505 \circ$ & $0.505 \circ$ & 0.016 \\
\hline 80 & 0.0710 & 0.0710 & 0.3820 & 0.3820 & 0.016 \\
\hline 90 & 0.0235 & 0.0198 & 0.2405 & 0.2020 & $9.896-10$ \\
\hline
\end{tabular}

TABLE VII

Alcohol: $\mathrm{NaCl}$ at $30^{\circ}$

\begin{tabular}{|c|c|c|c|c|c|}
\hline$\%$ Alc. & $y^{1}$ calc. & $y^{\prime}$ obs. & y calc. & y obs. & $\log \mathrm{C}$. \\
\hline 0 & 0.2650 & $0.265^{\circ}$ & 0.3605 & 0.3605 & 8.882-10 \\
\hline 5 & 0.2459 & 0.2459 & 0.3429 & 0.3430 & 8.882-10 \\
\hline IO & 0.2267 & 0.2266 & 0.3260 & 0.3257 & $8.88 \mathrm{I}-\mathrm{IO}$ \\
\hline 20 & o. I905 & O.1905 & 0.2940 & 0.2940 & $8.882-10$ \\
\hline 30 & o. I 560 & O. I 567 & 0.2637 & 0.2653 & 8.887 -10 \\
\hline 40 & o. I 234 & o. I 245 & 0.2347 & $0.237^{\circ}$ & $8.889-10$ \\
\hline $5^{\circ}$ & 0.0934 & 0.09 .34 & $0.206 \mathrm{I}$ & 0.2060 & $8.88 \mathrm{I}-10$ \\
\hline-1 & $---1----$ & -- - - - & -ー-- - - - & $---1-1$ & - \\
\hline 60 & 0.0636 & 0.0636 & o. I 698 & o. I 696 & 9.459-IO \\
\hline 70 & 0.0360 & 0.0368 & O.I 24 I & O. I 275 & $9.473-10$ \\
\hline 80 & 0.0160 & $0.015^{6}$ & 0.0818 & 0.0795 & $9 \cdot 446-10$ \\
\hline 90 & 0.0042 & 0.0043 & 0.0416 & 0.0430 & $9 \cdot 476-10$ \\
\hline
\end{tabular}

$$
\begin{array}{ll}
(\mathrm{x}+0.53) \mathrm{y}^{1.9}=\mathrm{C}_{1} & \log \mathrm{C}_{1}=8.882-10 \\
(\mathrm{x}+0.53) \mathrm{y}^{1,1}=\mathrm{C}_{2} & \log \mathrm{C}_{2}=9.460-10
\end{array}
$$




\section{TABLE VIII}

Alcohol: $\mathrm{NaCl}$ at $40^{\circ}$

$$
\begin{array}{ll}
(x+0.58) y^{1.8}=C_{1} & \log C_{1}=8.929-10 \\
(x+0.58) y^{1.1}=C_{2} & \log C_{2}=9.494-10
\end{array}
$$

\begin{tabular}{|c|c|c|c|c|c|}
\hline$\%$ Alc. & $\mathrm{y}^{1}$ calc. & $y^{1}$ obs. & y calc. & y obs. & $\log \mathrm{C}$ \\
\hline 0 & 0.2668 & 0.2668 & 0.3639 & 0.3638 & $8.929-10$ \\
\hline 5 & 0.2482 & 0.2479 & 0.3475 & 0.3469 & $8.928-10$ \\
\hline IO & 0.2302 & 0.2290 & $0.33^{2} 3$ & 0.3300 & $8.925-10$ \\
\hline 20 & O. 1942 & o. 1946 & 0.3012 & 0.3020 & $8.93 \mathrm{I}-\mathrm{IO}$ \\
\hline 30 & 0.1601 & 0.1602 & 0.2721 & 0.2725 & $8.930-10$ \\
\hline 40 & O. I 273 & O. I 275 & $0.243 \mathrm{I}$ & 0.2437 & $8.931-10$ \\
\hline 50 & 0.0969 & 0.0967 & 0.2146 & 0.2142 & $8.927-10$ \\
\hline 60 & 0.0665 & 0.0665 & 0.1782 & & \\
\hline 70 & $\begin{array}{l}0.0005 \\
0.037^{8}\end{array}$ & $\begin{array}{l}0.0605 \\
0.0387\end{array}$ & $\begin{array}{l}\text { O.I782 } \\
\text { O.I3IO }\end{array}$ & $\begin{array}{l}\text { O. I } 783 \\
\text { o. I } 343\end{array}$ & $\begin{array}{l}9494 \text {-Iо } \\
9.505 \text {-Iо }\end{array}$ \\
\hline 80 & $0.017 \mathrm{I}$ & 0.0169 & 0.0869 & 0.0862 & $9.490-10$ \\
\hline 90 & 0.0044 & 0.0050 & 0.0445 & 0.0510 & $9.560-10$ \\
\hline
\end{tabular}

\section{TABLE IX}

Alcohol: $\mathrm{KBr}$ at $30^{\circ}$

\begin{tabular}{|c|c|c|c|c|c|}
\hline$\%$ Alc. & $\mathrm{y}^{1}$ calc. & $y^{1}$ obs. & y calc. & y obs. & $\log C$ \\
\hline $\mathrm{o}$ & 0.4162 & 0.4162 & 0.7130 & 0.7130 & $9 \cdot 329-10$ \\
\hline 5 & $0.3^{897}$ & 0.3898 & 0.6720 & 0.6725 & $9.330-10$ \\
\hline 10 & 0.3633 & 0.3633 & 0.6340 & 0.6340 & $9 \cdot 329-10$ \\
\hline 20 & 0.3109 & 0.3109 & 0.5640 & 0.5640 & $9 \cdot 329-10$ \\
\hline 30 & 0.2598 & 0.2598 & 0.5015 & 0.5015 & $9 \cdot 329-10$ \\
\hline 40 & 0.2100 & 0.2124 & $0.443^{\circ}$ & 0.4495 & $9.34 \mathrm{I}-\mathrm{IO}$ \\
\hline 50 & 0.1625 & 0.1627 & 0.3880 & 0.3885 & $9.331-10$ \\
\hline & 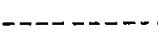 & - & -------- & $---\cdots$ & $-\cdots----1$ \\
\hline 60 & O.II 53 & O. I I 50 & 0.3260 & 0.3250 & $9.698-10$ \\
\hline 70 & 0.0677 & 0.0690 & 0.2420 & $0.247^{\circ}$ & $9 \cdot 7$ I I-IO \\
\hline 80 & 0.0316 & 0.0309 & o. 1630 & o. I 595 & $8.689-10$ \\
\hline 90 & 0.0086 & 0.0087 & 0.0868 & 0.0880 & $9.705-10$ \\
\hline
\end{tabular}

$$
\begin{array}{ll}
(x+0.42) y^{2}=C_{1} & \log C_{1}=9.329-10 \\
(x+0.42) y^{1.2}=C_{2} & \log C_{2}=9.700-10
\end{array}
$$


TABLE $X$

Alcohol: $\mathrm{KBr}^{-}$at $40^{\circ}$

$$
\begin{aligned}
& (x+0.50) y^{2}=C_{1} \quad \log C_{1}=9.468-10 \\
& (x+0.50) y^{1.2}=C_{2} \quad \log C_{2}=9.790-10
\end{aligned}
$$

\begin{tabular}{|c|c|c|c|c|c|}
\hline$\%$ Alc. & $y^{1}$ calc. & $\mathrm{y}^{1} \mathrm{obs}$. & y calc. & y obs. & $\log C$ \\
\hline $\mathrm{O}$ & 0.4340 & 0.4340 & 0.7665 & 0.7665 & $9 \cdot 468-10$ \\
\hline 5 & 0.4093 & 0.4085 & 0.7295 & 0.7270 & 9.465 -IO \\
\hline IO & 0.3843 & 0.3831 & 0.6935 & 0.6900 & $9 \cdot 464-10$ \\
\hline 20 & 0.3336 & 0.3327 & 0.6260 & 0.6230 & $9.464-10$ \\
\hline 30 & 0.2825 & $0.283^{2}$ & $0.5^{625}$ & $0.5^{645}$ & $9.47 \mathrm{I}-\mathrm{IO}$ \\
\hline 40 & 0.23 I 5 & 0.2322 & 0.5020 & 0.5040 & $9.472-10$ \\
\hline 50 & O. I 812 & O. I 8 I I & 0.4425 & 0.4425 & $9 \cdot 468-10$ \\
\hline 60 & & $-1-1$ & - & & $-1-1$ \\
\hline 70 & $\begin{array}{l}0.1305 \\
0.0777\end{array}$ & 0.0798 & $\begin{array}{l}.375 \\
0.2810\end{array}$ & $\begin{array}{l}0.5740 \\
0.2890\end{array}$ & $9.805-10$ \\
\hline 80 & 0.0367 & 0.0365 & 0.1905 & O. 1895 & $9.7^{87}$-IO \\
\hline 90. & O.OIOI & 0.0103 & O. 1025 & 0.1045 & $9.80 \mathrm{I}-\mathrm{IO}$ \\
\hline
\end{tabular}

I repeated the work of Bathrick on the solubility of sodium chloride, but the values of $n$ and of $A$ do not agree with those obtained by him, nor do his values of $n$ and $A$ for sodium nitrate at $40^{\circ}$ with acetone and with alcohol agree with mine determined at $30^{\circ}$. It is difficult to determine the value of $A$ with certainty, for unless all the measurements made are accurate it is possible to vary $A$ considerably and still have the formula hold almost equally well in each case.

The constant $A$ was found to be independent of the precipitating agent for any given salt and to vary only with the temperature. The constant $n$, however, seemed to be independent of the temperature, but to vary with the precipitating agent. These observations simply confirm the conclusions of Bathrick.

It will be seen that, in every case but one, two equations are needed to express the solubility. Bancroft considers that this indicates a change from water as the solvent to alcohol or acetone as the solvent. In almost every case the break comes between fifty and sixty percent alcohol, in some cases between forty and fifty percent. 
That is, when the aqueous alcohol contains less than fifty percent of alcohol, the water contained acts as the solvent; but when more alcohol is contained, then alcohol acts as the solvent. The values on the last curve are not as accurate as those on the first part, for the value $y$, the weight of salt in one gram of water, is not as accurately determined in solutions containing a large percentage of alcohol. The values of $y^{1}$, the amount of salt in one gram of saturated solution is determined directly, and a rather large error may be introduced when we change to $y$, as for instance in the ninety percent alcohol, when five grams of solution contain only about half a gram of water. Therefore, although $y$ is used directly in the equation, we must compare the values of $y^{1}$, as determined by experiment and as calculated from the formula, if we would judge correctly of the accuracy with which the equation states the facts obtained by experiment.

Thus far we have been dealing with the equilibrium between three substances; a solid and a liquid which are non-miscible, and water which is consolute with the liquid, but only partially miscible with the solid. If for the liquid another solid with a limited solubility in water be substituted, a similar equation $(x+A)(y+B)^{n}=C$ may be used, having one more constant. The constants, $A$ and $B$, however, are exactly the same as the constants $A$ and $A^{1}$ obtained from solubilities of the first type. Using this general formula Bathrick tabulated the results of $\mathrm{Nicol}^{1}$ on the solubility of mixtures of sodium and potassium chloride and of sodium chloride and nitrate. As I did not obtain the same values for $A$ that he did in the equations representing the solubility of sodium chloride and sodium nitrate in aqueous alcohol, I have recalculated the work of Nicol and find that I obtain as good an agreement with the values given by experiment as is obtained by Bathrick, and in some cases a better one. These results are given in Tables XI-XIV. I used the constant i 8 determined by Bathrick for potassium chloride.

rPhil. Mag, [5] 31, 369 (I891). 
TABLE XI

$\mathrm{NaCl}$ at $20^{\circ}$

$\mathrm{x}=\mathrm{g} \cdot \mathrm{NaNO}_{3} \quad \mathrm{y}=\mathrm{g} \cdot \mathrm{NaCl}$

$\left(\mathrm{x}+5^{\circ}\right)(\mathrm{y}+60)^{6.8}=\mathrm{C}_{1}$

$\log \mathrm{C}_{1}=\mathrm{I}_{5}$. I 75

\begin{tabular}{r|c|c}
\hline $\mathrm{x}$ & y calc. & y obs. \\
\hline 0.0 & 35.9 & 35.9 \\
$\mathrm{I} 4.2$ & 32.4 & 32.8 \\
28.3 & 29.7 & 29.8 \\
42.5 & 27.6 & 26.9 \\
54.5 & 26.0 & 26.0
\end{tabular}

TABLE XII

$\mathrm{NaNO}_{3}$ at $20^{\circ}$

$\mathrm{x}=\mathrm{g} . \mathrm{NaNO}_{3} \quad \mathrm{y}=\mathrm{g} . \mathrm{NaCl}$

$(\mathrm{x}+5 \mathrm{O})^{1.9}(\mathrm{y}+60)=\mathrm{C}_{2}$ $\log \mathrm{C}_{2}=4.55^{8}$.

\begin{tabular}{|c|c|c|}
\hline y & $x$ calc. & x obs. \\
\hline 0.0 & 87.6 & 87.6 \\
\hline 6.5 & 77.0 & $77 \cdot 3$ \\
\hline 13.0 & 68.3 & 68.5 \\
\hline 19,5 & 60.8 & 60.5 \\
\hline 26.0 & $54 \cdot 4$ & $54 \cdot 5$ \\
\hline \multicolumn{3}{|c|}{ TABLE XIII } \\
\hline \multicolumn{3}{|c|}{$\mathrm{NaCl}$ at $20^{\circ}$} \\
\hline \multicolumn{3}{|c|}{$\begin{array}{c}\mathrm{x}=\mathrm{g} \cdot \mathrm{NaCl} \quad \mathrm{y}=\mathrm{g} \cdot \mathrm{KCl} \\
(\mathrm{x}+\mathrm{I} 8)^{2.4}(\mathrm{y}+50)=\mathrm{C}_{1} \\
\log \mathrm{C}_{1}=5.855\end{array}$} \\
\hline $\mathrm{y}$ & $x$ calc. & $x$ obs. \\
\hline 0.0 & 35.9 & 35.9 \\
\hline 4. I & 34.2 & 34.4 \\
\hline 8.3 & 32.6 & 32.7 \\
\hline I 2.4 & - 3 I. 2 & $3^{1.3}$ \\
\hline 14.0 & 30.7 & 30.7 \\
\hline
\end{tabular}




\section{TABLE XIV}

$\mathrm{KCl}$ at $20^{\circ}$

$$
\begin{gathered}
\mathrm{x}=\mathrm{g} \cdot \mathrm{NaCl} \mathrm{y}=\mathrm{g} \cdot \mathrm{KCl} \\
(\mathrm{x}+\mathrm{I} 8)(\mathrm{y}+50)^{4}=\mathrm{C}_{2} \\
\log \mathrm{C}_{2}=\mathrm{r} 2.97^{\circ}
\end{gathered}
$$

\begin{tabular}{r|c|c}
\hline $\mathbf{x}$ & y calc. & y obs. \\
\hline 0.0 & 34.8 & 34.5 \\
6.5 & 28.6 & 29.7 \\
I 3.0 & 24.1 & 24.7 \\
19.5 & 20.6 & 20.4 \\
30.7 & I6. I & I 4.0
\end{tabular}

In these tables and all that follow, the values $x$ and $y$ represent the weight of salt found in roo grams of water rather than in one gram as previously. Where the temperature was lower than $30^{\circ}$ or $40^{\circ}$ a reduction was made in the value of $A$ as nearly as possible corresponding to the change observed in passing from $40^{\circ}$ to $30^{\circ}$. As has been said, the values of $A$ and $B$ are obtained from the solubility of the single salts in alcohol or acetone except that their value is multiplied by one hundred in these last equations, for the amount of salt in one hundred grams of water instead of the amount in one gram is used. Table XIV is not very satisfactory.

In Tables XV and XVI I have calculated some of the work of Ditte $^{\mathrm{l}}$ on the mutual solubility of bases and salts. The agreement between the calculated and the observed results is not very good; but wherever there is a very large discrepancy the points in question do not seem to lie on the empirical curve describing the solubility. The value of the constant $B$ for potassium hydroxide is probably not very accurate, for it was not determined from any previous experiments, but was calculated from the two sets of measurements here given.

xAnn. Chim. Phys. (7) 10, 556 ( 1897 ). 


\section{TABLE XV}

\section{$\mathrm{KCl}$ at $18^{\circ}$}

$\mathrm{x}=\mathrm{g} \cdot \mathrm{KOH} \quad \mathrm{y}=\mathrm{g} \cdot \mathrm{KCl}$

$(\mathrm{x}+\mathrm{I} 8)(\mathrm{y}+50)^{2.75}=\mathrm{C}$

$\log \mathrm{C}=6.548$.

\begin{tabular}{|c|c|c|}
\hline$x$ & y calc. & y obs. \\
\hline I. 8 & 3 I. 2 & 30.3 \\
\hline 2.3 & 30.4 & 28.9 \\
\hline 6.9 & $24 \cdot 7$ & 24.7 \\
\hline 9.7 & 21.9 & 22. I \\
\hline I 5.0 & 17.4 & I 7.5 \\
\hline 2 I. 6 & I3. I & I 2.3 \\
\hline 25.2 & I I. I & 10.8 \\
\hline 34.1 & $\begin{array}{l}7.1 \\
6.0\end{array}$ & 7.1 \\
\hline 34.6 & 6.9 & $\begin{array}{l}6.8 \\
3.0\end{array}$ \\
\hline $45 \cdot 9$ & $\begin{array}{l}3.0 \\
\text { I. I }\end{array}$ & 3.0 \\
\hline 52.7 & I. I & 2.2 \\
\hline 53.6 & 0.8 & 2.0 \\
\hline
\end{tabular}

\section{$\mathrm{KBr}$ at $17^{\circ}$}

$\mathrm{x}=\mathrm{g} \cdot \mathrm{KOH} \quad \mathrm{y}=\mathrm{g} . \mathrm{KBr}$

$(\mathrm{x}+32)(\mathrm{y}+50)^{1.45}=\mathrm{C}$.

$\log \mathrm{C}=4.494$

\begin{tabular}{r|r|r}
\hline $\mathrm{x}$ & $\mathrm{y}$ calc. & y obs. \\
\hline 3.6 & 56.9 & 55.9 \\
$\mathrm{I} 1.3$ & 43.4 & 43.4 \\
$\mathrm{I} 7.7$ & 34.9 & 35.8 \\
$23 . \mathrm{I}$ & 29.3 & $28 . \mathrm{I}$ \\
27.8 & 24.8 & 24.8 \\
43.5 & $\mathrm{I} 3.7$ & I3.7 \\
58.0 & 6.5 & 6.5
\end{tabular}

I have also found it possible to extend this equation to a slightly different case in which one of the salts is replaced by a gas viz. hydrochloric acid. Engel ${ }^{1}$ gives data for the solubility of quite a

\footnotetext{
${ }^{x}$ Ann. Chim. Phys. (6) 13, 370 (1889).
} 
large number of chlorides in hydrochloric acid of different concentrations. These results can be represented by the same general equation which has been used in the previous tables. I have tabulated the results for barium chloride, potassium chloride and sodium chloride. The value of $A$ for barium chloride was taken from the work of Bancroft, the value for potassium chloride from the work of Bathrick. The agreement between the calculated and the observed results is good. The variation in the case of barium chloride is somewhat larger than in the other two cases, as would be expected, for barium chloride crystallizes with water of crystallization, and would thus offer greater experimental difficulties.

\section{TABLE XVII}

\begin{tabular}{|c|c|c|}
\hline \multicolumn{3}{|c|}{$\mathrm{NaCl}$ at $0^{\circ}$} \\
\hline \multicolumn{3}{|c|}{$\begin{array}{c}x=g \cdot \mathrm{HCl} \quad \mathrm{y}=\mathrm{g} \cdot \mathrm{NaCl} \\
(\mathrm{x}+40)(\mathrm{y}+5 \mathrm{O})=\mathrm{C} \\
\log \mathrm{C}=2.537\end{array}$} \\
\hline $\mathrm{x}$ & y calc. & y obs. \\
\hline 0.00 & 36.1 & $3^{6 . I}$ \\
\hline $0.4 \mathrm{I}$ & $35 \cdot 3$ & $35 \cdot 3$ \\
\hline 0.74 & $34 \cdot 5$ & $34 \cdot 3$ \\
\hline 2.08 & 31.8 & 31.7 \\
\hline 3.79 & 28.7 & 28.8 \\
\hline 6.14 & $24 \cdot 7$ & 24.8 \\
\hline I 2.60 & I 5.5 & I 5.5 \\
\hline 23.37 & $3 \cdot 5$ & 3.9 \\
\hline
\end{tabular}

We have thus found the value of $A$ for any particular salt to be constant under quite varying conditions. The same value for $A$ may be used whether the salt be precipitated by alcohol, acetone, or by a base, an acid or another salt having a common ion. These experiments, however, serve to illustrate the fact that the value of $A$ can be determined with accuracy only by making very accurate solubility determinations.

The objection might be raised that almost any formula, containing as many arbitrary constants as these do, could be made to correspond with the experimental facts. This may be partly true in any 
particular case, e. g. five constants are used in the equations representing the solubility of sodium chloride in aqueous acetone and there are only about eleven values given. It is true even here, however, that if the value of $A$ is varied much, the equation represents the facts with much less accuracy. If the constant $A$ for potassium chloride is similarly determined, we may use these two constants in the equation describing the precipitation of sodium chloride by potassium chloride, then having but two arbitrary constants. In such a case we seldom have more than four or five measurements, so that it might be clained that the two constants were sufficient. However, the same value of $A$ may be used in the equations representing the precipitation of potassium chloride by potassium hydroxide or hydrochloric acid, and in these cases we have a rather large number of measurements made, over a considerable range of concentrations, and but two arbitrary constants are used.

\section{TABLE XVIII}

$\mathrm{KCl}$ at $0^{\circ}$

$$
\begin{gathered}
\mathrm{x}=\mathrm{g} \cdot \mathrm{HCl} \quad \mathrm{y}=\mathrm{g} . \mathrm{KCl} \\
(\mathrm{x}+12)(\mathrm{y}+50)^{2.6}=\mathrm{C} \\
\log \mathrm{C}=6.006
\end{gathered}
$$

\begin{tabular}{c|c|c}
$\mathrm{x}$ & $\mathrm{y}$ calc. & $\mathrm{y}$ obs. \\
\hline 0.0 & 28.5 & 28.5 \\
$\mathrm{I} .6$ & 24.9 & 24.9 \\
2.6 & 22.8 & 22.7 \\
2.8 & 22.4 & 22.4 \\
4.4 & $\mathrm{I} 9.6$ & $\mathrm{I} 9.3$ \\
9.2 & $\mathrm{I} 3 . \mathrm{I}$ & $\mathrm{I} 3 . \mathrm{I}$ \\
$\mathrm{I} 3.7$ & 8.6 & 8.2 \\
$\mathrm{I} 6.6$ & 6.2 & 6.2
\end{tabular}

It seems therefore as if these formulae would not always remain empirical, when we consider the relation that exists between them. It is, however, true that a very considerable variation is possible in the constants employed, if too great accuracy is not required. We cannot then determine these constants satisfactorily, nor be sure 
that they apply absolutely to the results obtained by experiment, till more accurate work is done on the solubility of mixed salts, bases or acids having a common ion. When a large amount of accurate data has been compiled, we shall then be able to test these equations and determine whether they really do describe the facts determined by experiment. If further work does show that these formulae are correct, then it may be possible later to derive the constants which are now only empirical.

\section{TABLE XIX}

$$
\mathrm{BaCl}_{a} \text { at } 0^{\circ}
$$

$$
\begin{gathered}
\mathrm{x}=\mathrm{g} \cdot \mathrm{HCl} \quad \mathrm{y}=\mathrm{g} \cdot \mathrm{BaCl}_{2} \\
(\mathrm{x}+\mathrm{r} 5)(\mathrm{y}+50)^{1.4}=\mathrm{C} \\
\log \mathrm{C}=3.85^{2}
\end{gathered}
$$

\begin{tabular}{r|r|r}
\hline $\mathrm{x}$ & $\mathrm{y}$ calc. & y obs. \\
\hline & & \\
\hline O.0 & $3 \mathrm{I} .5$ & $3 \mathrm{I} .6$ \\
O.4 & $30 . \mathrm{I}$ & 30.5 \\
$\mathrm{I} . \mathrm{I}$ & 27.5 & 28.6 \\
$\mathrm{I} .9$ & 24.9 & 25.6 \\
5.5 & $\mathrm{I} 5.2$ & $\mathrm{I} 5.4$ \\
7.3 & $\mathrm{II} .4$ & $\mathrm{II} .2$ \\
8.8 & 8.6 & 7.3 \\
I 2.5 & 2.9 & 3.0
\end{tabular}

In an aqueous solution, when a salt is precipitated by another salt having a common ion, two equations are required to describe the phenomena, according as one salt or the other is precipitated; and we have two curves, along one curve the one salt is precipitated, and along the other curve the other salt. When a salt is precipitated by some liquid consolute with water, two equations are also required, and this is explained by a change in the solvent, thus furnishing a point toward distinguishing between the solvent and the solute When a salt is precipitated by a base or an acid we find but one equation is required. This is as would be expected, as long as the base or the acid is not precipitated. However, we might also expect theoretically to obtain another curve, and that hydrochloric acid gas 
would be driven from a concentrated solution of hydrochloric acid by means of sodium chloride according to a nother formula. This would occur in the solution which separates as a second liquid phase. It must be remembered that the addition of sodium chloride always increases the partial pressure of hydrochloric acid in the vapor phase.

The results of this paper have then simply served to strengthen the points already brought out:

I. The behavior of ternary mixtures of the type here mentioned can be described by equations of the general form $(x+A) y^{n}=C$ and $(x+A)(y+B)^{n}=C$;

2. The constant $n$ is independent of the temperature but varies with the precipitating agent;

3. $A$ and $B$ vary with the temperature and are each characteristic of one of the non-miscible substances, $A$ being a function of $y$, and $B$ of $x$.

Comell University 